\title{
Numerical Analysis Of Stress Distribution On Artificial Hip Joint Due To Jump Activity
}

\author{
Gilar Pandu Annanto ${ }^{1, *}$, Eko Saputra ${ }^{1}$, J Jamari $^{1}$, Athanasius Priharyoto Bayuseno ${ }^{1}$, Rifky Ismail ${ }^{1}$, Mohammad \\ Tauviqirrahman ${ }^{1}$, and Iwan Budiwan Anwar ${ }^{2}$ \\ ${ }^{1}$ Department of Mechanical Engineering, Faculty of Engineering, Diponegoro University, Semarang - Indonesia \\ ${ }^{2}$ Orthopaedic and Traumatology Department, Prof Dr R. Soeharso Orthopaedic Hospital, Surakarta, Indonesia
}

\begin{abstract}
Due to degenarative disorder of articular cartilage, hip joint need to be replaced with an artificial hip joint. Currently, the modular design of artificial hip joint become popular in the procedure because the modular type's provide flexibility for the surgeon. But, there were several report about the failure of modular version, and the failure was likely to happen on the neck part. The main focus of this research was to ensure the design safety of present artificial hip joint using FEM (Finite Element Method). The present artificial hip joint was loaded with force that occurred due to jump activity, and there were 3 type of materials that used in this research (Titanium Alloy (Ti-6Al-4V), Cobalt - Chrome alloy, and stainless steel (SS) 316L). The result is maximum stress that occurred on Ti-6Al-4V, Co-Cr alloy, and SS316L were 296.13 MPa, 294.02 MPa, and 294.51 MPa, respectively. The Ti-6Al-4V perform the best among the others with the safety factor of 2.7 .
\end{abstract}

Keywords: artificial hip joint; FEM; failure;

\section{Introduction}

As the weight-bearing and shock absorbing structures in human body, hip joint become one of the most important component in human body during daily activities (jumping, walking, running etc) [1]. Due to degenerative disorder of the articular cartilage (Ostoearhritis), An artificial hip joint need to be placed in order to replace the damaged hip joint [2]. Currently, the modular design of artificial hip joint become poopular in the procedure [3]. Modularity provide the surgeon with a deal of freedom to account for complex anatomy and easily change stem version length and offset [4]. But there were several report about the failure of the modular version of artificial hip joint. The neck part in the femoral stem was the part where the failure happen at most [3]-[5]..

In order to assure the safety of the artificial hip joint design, detailed analyses need to be performed with load variations[6]. A dynamics finite element method analysis can be performed as an alternative solution to predict the artificial hip joint capability, using the magnitude of body weight as a load [6]-[9]. However, the load which the artificial hip joint take can vary depends of the activity, and this parameter can not be ignored when estimating the failure of artificial hip joints due to the fatigue. There were some research which had been done in order to confirm the trustworthiness of artificial hip joint based on several activitis, for example salat movement [10]-[12] and daily life activities [13][15]. Predicting the maximum stress on the artificial hip joint during the jumping movement (which in category of high-impact movement)[16] is the main goal of this research.

\section{Material and Method}

\subsection{Material model}

The FEM model that presented in this study consist of steam head, stem rod and locked screw. The locked screw components is assumed to be rigid. The stem head and stem rod are modeled as an elastic-plastic material. Based on previous research, there are 3 material's options used in this study, Titanium Alloy (Ti-6Al-4V), Cobalt-Chrome alloy (Co-Cr), and Stainless Steel 316L (SS 316L) [4], [6]-[8], [14], [15], [17]-[21]. Table 1 show the properties of the material that used in the analysis.

Table 1. The properties of Titanium Alloy (Ti-6Al-4V), Cobalt Chrome alloy (Co-Cr Alloy), Stainless Steel (SS) $316 \mathrm{~L}$

\begin{tabular}{|c|c|c|c|c|}
\hline Material & $\begin{array}{c}\boldsymbol{E} \\
\text { (GPa) }\end{array}$ & $\mathbf{v}$ & $\begin{array}{c}\boldsymbol{\sigma} \\
\text { (MPa) }\end{array}$ & Ref. \\
\hline Ti-6Al-4V & 110 & 0.32 & 800 & Ref. [7] \\
\hline Co-Cr & 220 & 0.3 & 720 & Ref. [7] \\
\hline 316L & 193 & 0.25 & 290 & Ref. [22] \\
\hline
\end{tabular}

To calculate the effect generated by the bone behaviour, different material properties are applied on both inner and outer side of the bone. An isotropic material model is applied on the inner side and represented as cancellous bone $\left(\mathrm{G}_{\mathrm{xz}}=\mathrm{G}_{\mathrm{yz}}=3.3 \mathrm{GPa}, \mathrm{G}_{\mathrm{xy}}\right.$

* Corresponding author: gilarpanduannanto@gmail.com 
$\left.=3.6 \mathrm{GPa} ; \mathrm{E}_{\mathrm{x}}=\mathrm{E}_{\mathrm{y}}=11.5 \mathrm{GPa}, \mathrm{E}_{\mathrm{x}}=17 \mathrm{GPa}\right)$. A linear isotropic material model is applied on the outer side of the bone and represented as cortical bone $(\mathrm{E}=2.13 \mathrm{GPa}$ and $v=0.3$ ). A linear isotropic material model is applied on the Cement and represented as polymethyl methacrylate with the properties of $\mathrm{E}=2.7 \mathrm{GPa}$ and $\mathrm{v}=$ $0.35[7]$.

\subsection{Finite Element Method}

\subsubsection{Geometry}

The artificial hip joint design that developed by Diponegoro University was selected as the geometrical model on this research. The diameter and length of the femoral neck is $12 \mathrm{~mm}$ and $23.5 \mathrm{~mm}$, respectively. The stem rod diameter is $11 \mathrm{~mm}$ with $142 \mathrm{~mm}$ in height. The bone-cement mantle is aprroximately $4 \mathrm{~mm}$ in thickness. Fig. 1 shows geometrical model for current study. The meshes which is used in the study, using tetrahedron type on the element with the number of element is 8524 and the total nodes is 16055

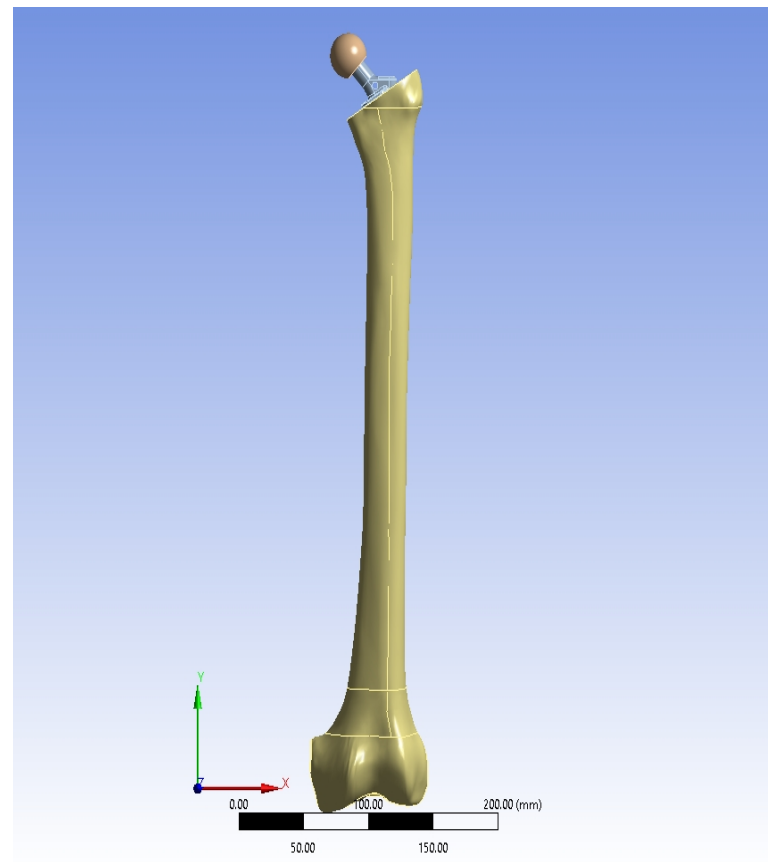

Fig. 1 The geometrical modelling of present artifical hip joint

\subsubsection{Boundary Condition}

The determination of loading model was based on senalp et al. [7] works. In the dynamics analysis, the surface of the femoral head was applied by $F_{\text {dynamics. }}$ $F_{\text {dynamics }}$ represent the load that occurred due to body weight in jumping activity. $1.25 \mathrm{kN}$ of load that caused by the abductor muscle was applied on the proximal area of the great trochanter with $20^{\circ}$ angle. The bottom of stem road was loaded with $250 \mathrm{~N}$ of load that caused by ilio tibial tract. Distal end of the femur was constrained so it was not allowed to move in the horizontal direction. Fig. 2 shows the direction of the applied load on the assembly of bone-cement-prosthesis.

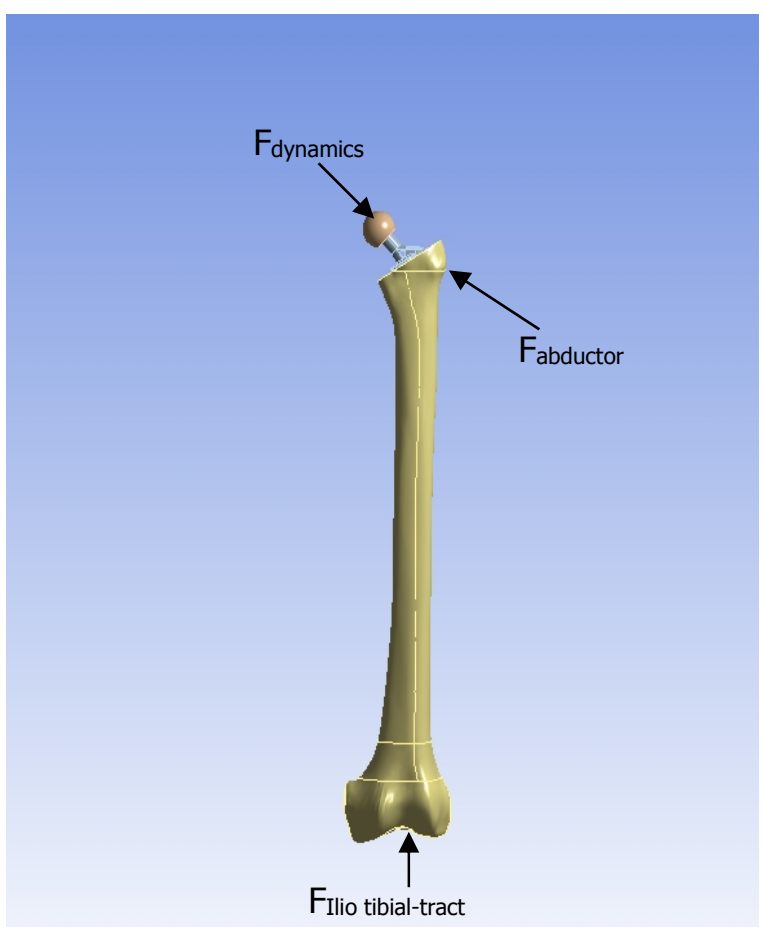

Fig. 2 The load modeling of the artifical hip joint that has been assembled in the femur bone.

The dynamic forces that will be applied in present study were the forces that occurred on hip joint during the jumping activity. The values were taken from orthoload.com. Orthoload was a site that provided information about orthopaedic implants [23]. Fig. 3. Show the load that will be applied on the present artificial hip joint.

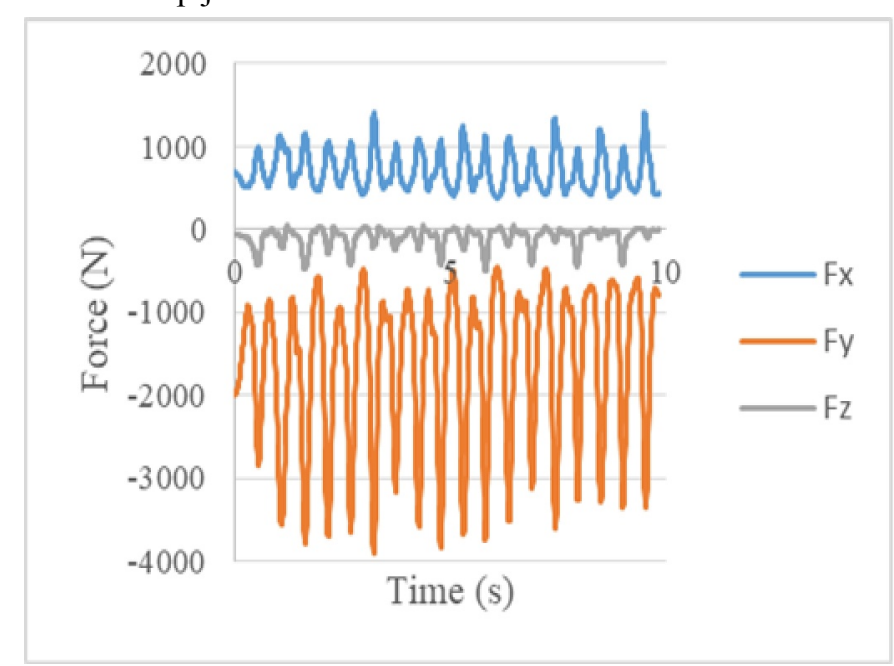

Fig. 3 The dynamic force that occured during jumping activity.

\section{Result and Discussion}

\subsection{Validation}

A validation of simulation need to be performed in order to ensyre the validity of the developed model of 
simulation. The work that selected as a validation was the work of Sivasankar[15]. The works was to define the maximum stress that occurred on the artificial hip joint during normal walking on a study participant with body weight $702 \mathrm{~N}$. The forces that applied on the artificial hip joint were taken from several activity likes fast walking, normal walking, slow walking, and downstairs. The comparison of maximum stress that occurred on the sivasankar model and present model can be seen on Fig. 4. The average deviation between these two model is about $3.8 \%$. The predicted maximum stress from developed model is almost similar with the predicted maximum stress from the corresponding literature[15].

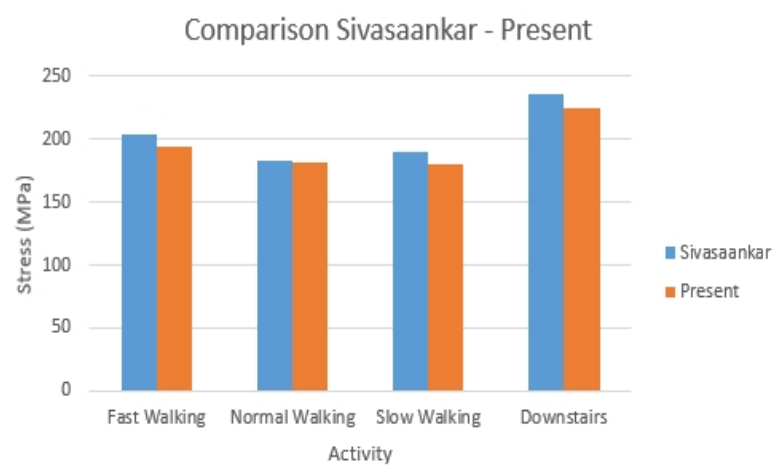

Fig. 4 Comparison between sivasankar model - present model.

\subsection{Jumping Activity}

Fig. 5, Fig. 6, and Fig. 7 show the stress distribution over the present artificial hip joint due to the load that occurred during the jumping activity on Ti-6AL-4V, Co$\mathrm{Cr}$, and SS 316L, respectively. From the Fig. 5, Fig. 6 and Fig. 7, it can be seen that the maximum stress was occurred on the neck of the artificial hip joint.

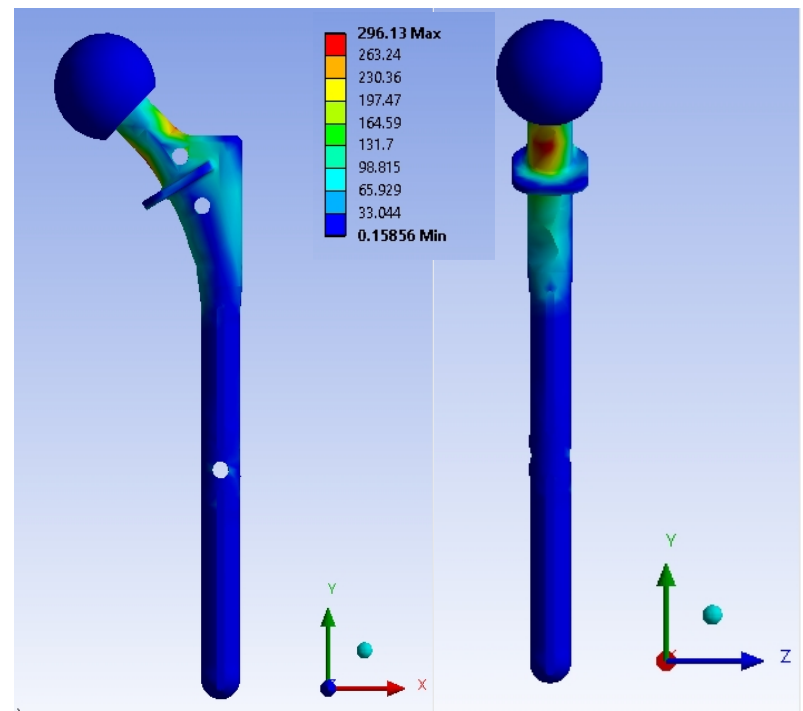

Fig. 5 Distribution of stress over the present artificial hip joint with titanium alloy (Ti-6Al-4V) material.

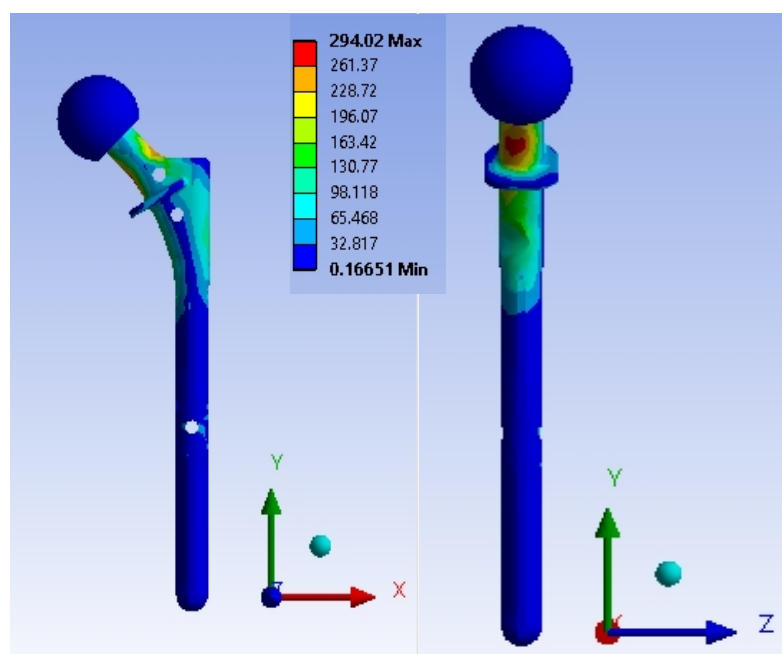

Fig. 6 Distribution of stress over the present artificial hip joint with $\mathrm{Co}-\mathrm{Cr}$ Alloy material

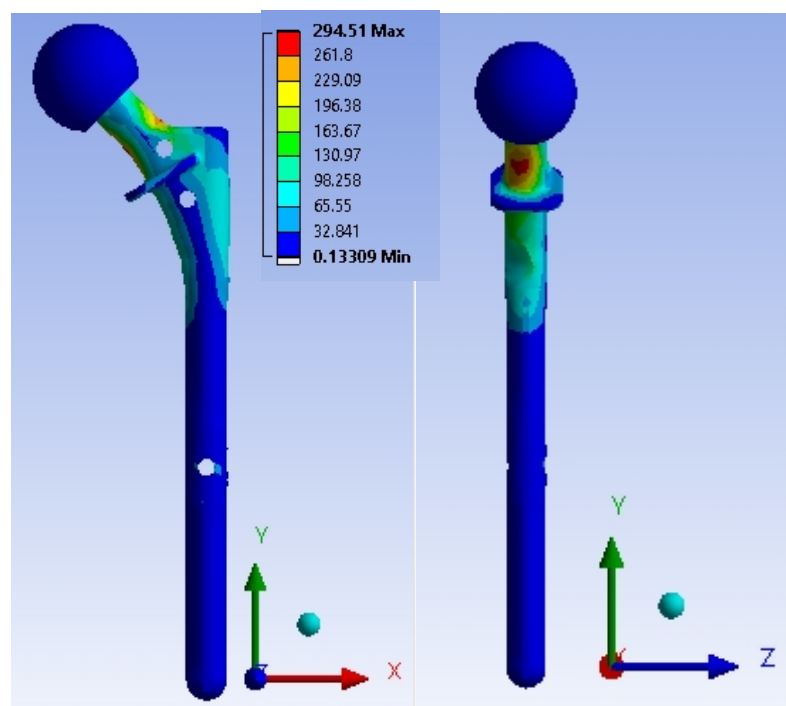

Fig. 7 Distribution of stress over the present artificial hip joint with SS $316 \mathrm{~L}$ material.

Fig. 8 Shows the stress values that works on present artificial hip joint. The maximum value of stress, occurred on $5.8 \mathrm{~s}$. The maximum stress on titanium alloy (Ti-6Al-4V), cobalt chrome (Co-Cr), and stainless steel 316L were 296.13 MPa, 294.02 $\mathrm{MPa}$, and 294.51 MPa, respectively. Titanium alloy $(\mathrm{Ti}-6 \mathrm{Al}-4 \mathrm{~V})$ perform the best among the others. With the yield stress value is 800 $\mathrm{MPa}$, it had a safety factor at 2.7. Meanwhile, the stainless steel $316 \mathrm{~L}$ perform the worst. The maximum stress that works on stainless steel $316 \mathrm{~L}$ artificial hip joint was $294.51 \mathrm{MPa}$, not too different with the stress that occured on titanium alloy (Ti-6Al-4V) and cobalt chrome (Co-Cr), but stainless steel $316 \mathrm{~L}$ only had maximum yield stress value at $290 \mathrm{MPa}$, with the current stress, the safety factor was only 0.98 , and predicted that the stainless steel $316 \mathrm{~L}$ artificial hip joint will be plastically deformed. Based on the analysis, it's not suggested to perform jumping movement on artificial hip joint that manufactured using stainless steel $316 \mathrm{~L}$ material.

\footnotetext{
* Corresponding author: gilarpanduannanto@gmail.com
} 


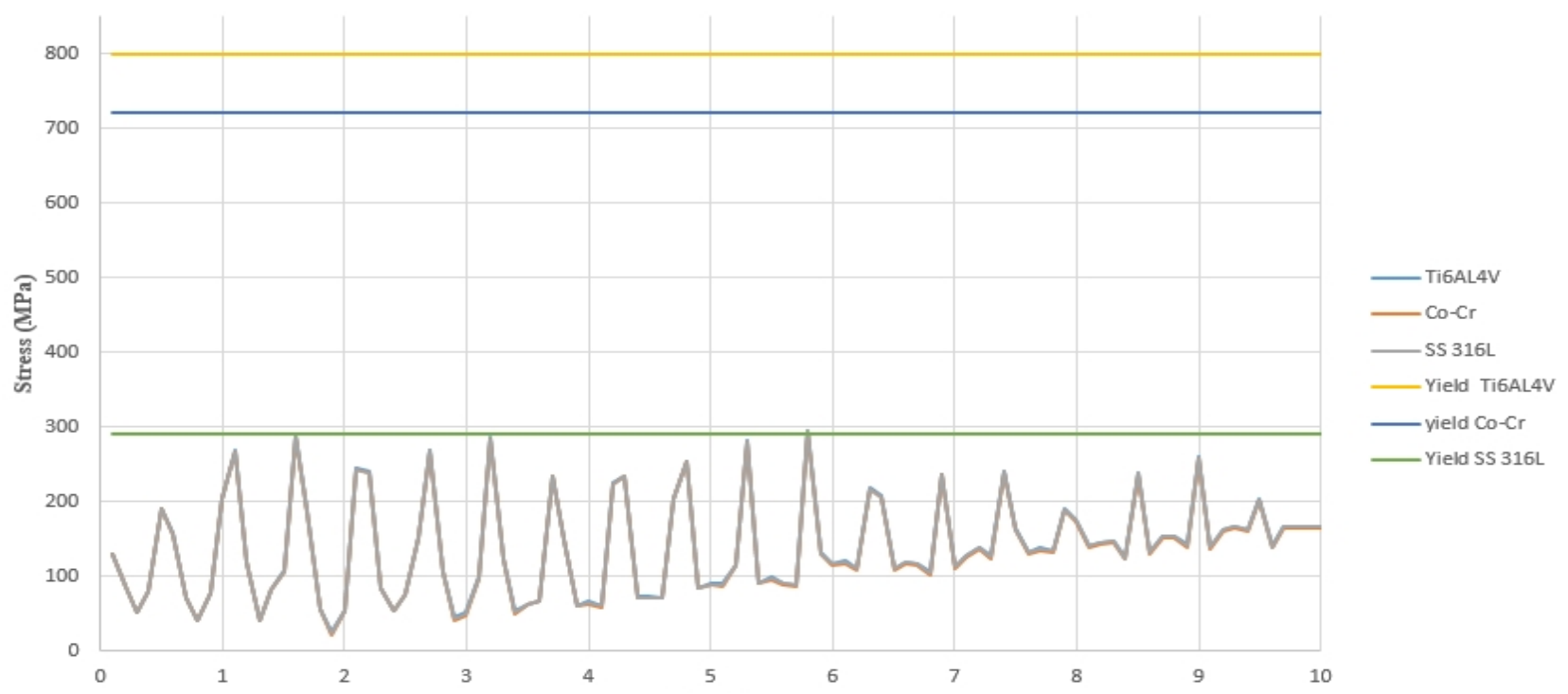

Fig. 8. Stress over the time on artificial hip joint during jumping activity

\section{Conclusion}

This paper investigated the stress that occurred on the artificial hip joint due to load from jumping movement. The present artficial hip joint was the modular type and the material was variated using Ti$6 \mathrm{Al}-4 \mathrm{~V}$, Co-Cr, and SS 316L. Based on result, it can be stated that artificial hip joint that uses Ti-6Al-4v and Co$\mathrm{Cr}$ can withstand from the load that produced by the jumping activity, unlike the other, SS 316L was not recommended for the jumping activity. It was predicted to plastically deformed due to the value of stress that occurred was larger than the value of yield stress. For further research, the artificial hip joint should be tested using fatigue parameter to predict the cycle of life before its failed.

\section{References}

D. J. Cleather, J. E. Goodwin, and A. M. J. Bull, "Hip and knee joint loading during vertical jumping and push jerking," Clin. Biomech., vol. 28, no. 1, pp. 98103, 2013.

2 K. Sinusas, "Osteoarthritis: Diagnosis and Treatment," $B m j$, vol. 1, no. 5222, pp. 355-356, 1961.

3 K. Uchiyama et al., "Early fracture of the modular neck of a MODULUS femoral stem," Arthroplast. Today, vol. 3, no. 2, pp. 93-98, 2017.

4 B. M. Stronach, M. D. Roach, and K. R. St. John, "Failure of Emperion modular femoral stem with implant analysis," Arthroplast. Today, vol. 2, no. 1, pp. 11-14, 2016.

5 K. Rueckl, P. K. Sculco, J. Berliner, M. B. Cross, C. Koch, and F. Boettner, "Fracture risk of tapered modular revision stems: A failure analysis," Arthroplast. Today, pp. 11-16, 2017.

6 K. Colic, A. Sedmak, A. Grbovic, U. Tatic, and S. Sedmak, "Finite Element Modeling of Hip Implant Static Loading," Procedia Eng., vol. 149, no. June, pp. 257-262, 2016
A. Z. Senalp, O. Kayabasi, and H. Kurtaran, "Static, dynamic and fatigue behavior of newly designed stem shapes for hip prosthesis using finite element analysis," Mater. Des., vol. 28, no. 5, pp. 1577-1583, 2007.

H. Jiang, "Static and Dynamic Mechanics Analysis on Artificial Hip Joints with Different Interface Designs by the Finite Element Method," J. Bionic Eng., vol. 4, no. 2, pp. 123-131, 2007.

9 P. J. Prendergast, "Finite element models in tissue mechanics and orthopaedic implant design," Clin. Biomech., vol. 12, no. 6, pp. 343-366, 1997.

10 J. Jamari, R. Ismail, E. Saputra, S. Sugiyanto, and I. B. Anwar, "The Effect of Repeated Impingement on UHMWPE Material in Artificial Hip Joint during Salat Activities," Adv. Mater. Res., vol. 896, pp. 272275, 2014.

11 R. Ismail, E. Saputra, and M. Tauviqirrahman, "Numerical Study of Salat Movements for Total Hip Replacement Patient," Appl. Mech., vol. 493, pp. 426431, 2014.

12 E. Saputra, I. B. Anwar, J. Jamari, and E. van der Heide, "A Bipolar Artificial Hip Joint Design for Contact Impingement Reduction," Adv. Mater. Res., vol. 1123, pp. 164-168, 2015.

13 E. Saputra, I. B. Anwar, J. Jamari, and E. Van Der Heide, "Finite element analysis of artificial hip joint movement during human activities," Procedia Eng., vol. 68, pp. 102-108, 2013.

14 H. E. F. El-shiekh, "Finite Element Simulation of Hip Joint Replacement under Static and Dynamic Loading," no. March, pp. 1-293, 2002.

15 M. Sivasankar, "Failure Analysis of Hip Prosthesis," no. November, 2007.

16 L. A. Vogel, G. Carotenuto, J. J. Basti, and W. N. Levine, "Physical activity after total joint arthroplasty," Sports Health, vol. 3, no. 5, pp. 441450, 2011.

17 N. Bonnheim, H. Gramling, M. Ries, S. Shukla, B. Iliescu, and L. Pruitt, "Fatigue fracture of a cemented Omnifit $\mathrm{CoCr}$ femoral stem: implant and failure analysis," Arthroplast. Today, vol. 3, no. 4, pp. 234 238, 2017.

18 D. Bennett and T. Goswami, "Finite element analysis of hip stem designs," Mater. Des., vol. 29, no. 1, pp.

* Corresponding author: gilarpanduannanto@gmail.com 
45-60, 2008.

19 T. Madras, "Finite Element Based Design Of Hip Joint Prosthesis Finite Element Based Design Of Hip Joint Thesis Submitted In Partial Fulfillment Of The Requirements For The Degree Of Master Of Technology In National Institute Of Technology, Indonesia" No. July 2011, 2016.

20 A. Kumar, R. Kumar, and A. Dixit, "Numerical Analysis of Hip Joint Implant," Mater. Today Proc., vol. 2, no. 4-5, pp. 1649-1656, 2015.
K. R. Cidambi, S. L. Barnett, P. R. Mallette, J. J. Patel, N. A. Nassif, and R. S. Gorab, "Impact of Femoral Stem Design on Failure After Anterior Approach Total Hip Arthroplasty," J. Arthroplasty, 2017.

P. D. Harvey "Engineering Properties of Steels," American Society for Metals, Metals Park OH, 1982. P. Damm and A. Bender, "Hip Joint Database," Berlin, 2018. [Cited 12 July 2018]. Available: https://orthoload.com/database/ 